\title{
Polyurethanes Obtained by Reacting 1,6-HDI with Monoglycerides from Babassu Oil: A DFT Study
}

\author{
Francisco I. da Silva, ${ }^{a, b}$ Égil Sá $^{\circledR *, c, d}$ and José M. E. de Matos ${ }^{\circledR a}$ \\ ${ }^{a}$ Departamento de Química, Universidade Federal do Piauí, 64049-505 Teresina-PI, Brazil \\ ${ }^{b}$ Instituto Federal do Piauí, 64750-000 Paulistana-PI, Brazil \\ 'Laboratório de Química Teórica, Universidade Federal do Piauí, 64049-505 Teresina-PI, Brazil \\ ${ }^{d}$ Universidade Federal do Delta do Parnaíba, Campus Ministro Reis Veloso, \\ 64202-020 Parnaíba-PI, Brazil
}

\begin{abstract}
This is a density functional theory (DFT)-based (M06) study on the polyurethane formation from 1,6-hexamethylenediisocyanate (1,6-HDI) reacting with the monoacylglycerol obtained from the babassu oil. As the lauric acid is the most abundant fatty acid in the vegetable oil, the 2-monolaurin was chosen to scrutinize the polyurethane formation. An analysis of two different mechanisms (stepwise and concerted) showed the concerted pathway as the most favorable, which involves the transference of the hydrogen in the 2-monolaurin to a nitrogen atom in the 1,6-HDI. Finally, the dimerization process takes place by coupling of urethane blocks, instead of growing the chain by adding 1,6-HDI after 2-monolaurin (or vice versa).
\end{abstract}

Keywords: DFT, polyurethanes, babassu oil, 1,6-HDI

\section{Introduction}

Polyurethanes (PUs) are one of the most important types of polymers in modern life, with a wide range of applications such as furniture, footwear, construction, automotive and so on..$^{1-3}$ Due to the versatility and utility, PUs account for around 5\% of the worldwide polymer production, which corresponds to around 16 million tons of raw materials produced annually. ${ }^{4,5} \mathrm{PUs}$ are a broad class of polymers showing as transversal aspect the presence of the urethane group (-NHCO-O-), ${ }^{6}$ which the preparation is based on the original work of Bayer, ${ }^{7}$ by a straightforward route that reacts diols with diisocyanates. ${ }^{7}$

PUs show thermoplastic, elastomeric and thermoset behavior depending on their chemical and morphological properties, that can be tuned by changing the type and functionality of the polyol and/or isocyanate precursors, allowing large potential types of polymers that can provide a diverse usage. In industry, only a few polyisocyanates are used, usually obtained from petroleum sources, while a variety of polyols are available. In this way, the polyol typically determines the properties of the polyurethane. ${ }^{2,5}$

*e-mail: egil.sa@ufpi.edu.br
The rising interest and concern about environmental matters, such as global warming and waste, plus the depletion of fossil and petroleum resources, turn the attention to safer and cleaner products and processes using renewable feedstocks. Among others, natural oils provide an abundant source to replace petrochemicals or to be directly used in bioinspired materials, including polymer synthesis. Nowadays there are many alternatives for the preparation of thermosets and thermoplastic polymers based on plant sources, such as soybean, canola, rapeseed, palm, sunflower, corn, and linseed oils. ${ }^{8-11}$ In this way, these vegetable oils are becoming very important as a renewable resource for the preparation of the polyols, since they are composed of triacylglycerols, necessary for polyurethane synthesis.

Another possibility of vegetable oils as a source of triacylglycerols is the babassu oil, obtained from the nuts of the babassu palm (Orbignya speciosa). This is a natural tree from the Brazilian biomes Amazon, Caatinga and Atlantic Forest, scattered throughout Maranhão, Tocantins, Pará and Piauí states. Derivatives of the babassu palm have a considerable economic impact in the region above mentioned, being useful in industry, coal, recycled paper, handicraft works, building and the most importantly, the extraction of the oil. ${ }^{12,13}$ The main components of babassu 
oil are triglycerides of lauric acid $(41.6 \%)$, myristic acid $(17.9 \%)$, oleic acid $(13.3 \%)$ and palmitic acid $(9.4 \%) .^{14,15}$ Those triglycerides can be converted into the monoglyceride via glycerolysis. ${ }^{16,17}$

Despite the importance of the polyurethane formation in the absence of any catalysts, there is still not a full understanding of the mechanism for this reaction. Some authors ${ }^{18}$ claim a concerted mechanism for the reaction, while others ${ }^{19,20}$ advocate for a stepwise mechanism to rule the process. In this way, this work aims at understanding the mechanistic parameters for the reaction of the 2-monoglycerides, derived from the babassu oil, with 1,6-hexamethylenediisocyanate (1,6-HDI).

\section{Methodology}

To assess the reactivity of monoglycerides with 1,6-HDI, we do here a theoretical approach based on density functional theory (DFT). All structure optimizations were performed using the Gaussian 09 suite of programs. ${ }^{21}$ B3LYP $^{22,23}$ (Becke, 3-parameter, Lee-Yang-Parr) was the exchange-correlation functional chosen along with the 6-311G basis set. ${ }^{24,25}$ Frequency calculations were done to ensure the nature of the optimized geometries: minimum, showing zero imaginary frequency, and transition state (TS) with a single imaginary frequency. Free energy corrections were determined using vibrational frequencies assuming a standard state of $1 \mathrm{~atm}$ and $298.15 \mathrm{~K}$ at B3LYP/6-311G level of theory. We have performed intrinsic reaction coordinate calculations to ensure that the located transition states were indeed correspondent to the reaction steps we were interested in. The energies reported in this text are the free Gibbs energy.

\section{Results and Discussion}

As said above, the main goal of this work is to understand the mechanism for the formation of polyurethanes from 2-monoglycerides derived from the babassu oil with 1,6-HDI. In this work we have explored two possible mechanisms for the formation, shown in Scheme 1: path A is a concerted mechanism and B is a stepwise possibility. ${ }^{18-20}$

Since the lauric acid is the most abundant fatty acid in the babassu oil, we investigate the reaction of its derivative 2-molaurin with 1,6-HDI for the formation of the polyurethanes. The energetic profile of the concerted mechanism is shown in Figure 1.

The concerted pathway has only one transition state (TS), where the breaking of the $\mathrm{O}-\mathrm{H}$ and formation of the $\mathrm{N}-\mathrm{H}$ takes place at the same time. In this species the $\mathrm{O}-\mathrm{H}$ length is $1.22 \AA$, while in the reactant 2-monolaurin

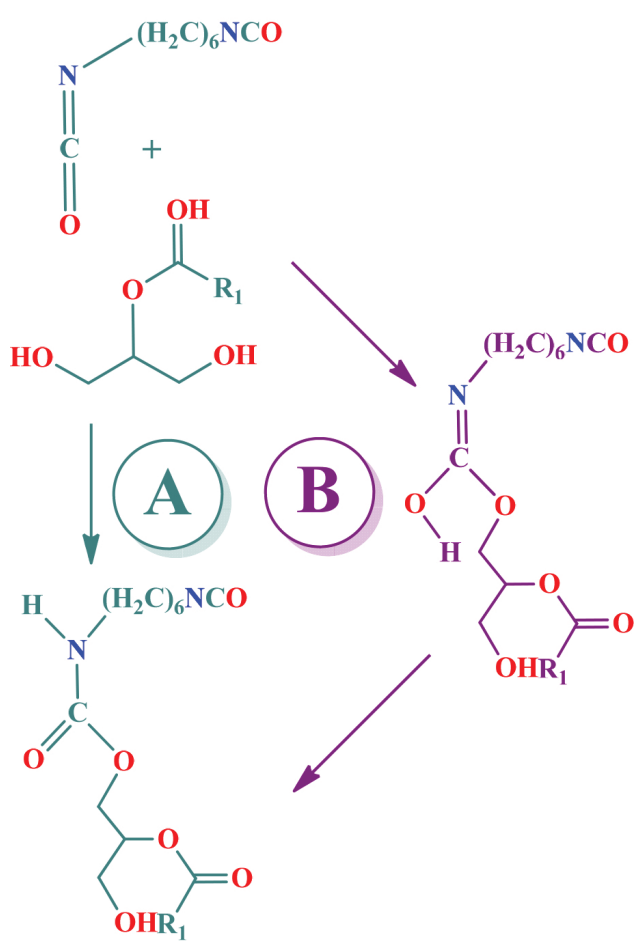

Scheme 1. Potential mechanisms for the formation of polyurethanes from 2-monoglycerides derived from the babassu oil with 1,6-HDI: (path A) concerted and (path B) stepwise.

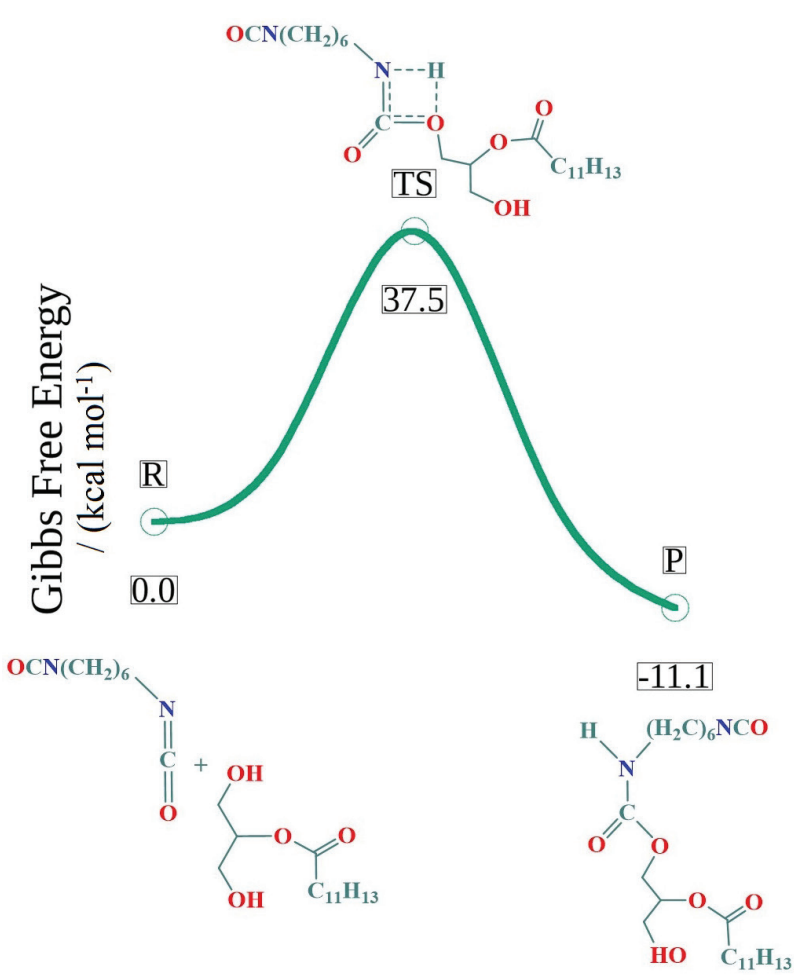

Figure 1. Free energy profile for the reaction of 2-monolaurin with 1,6-HDI by the concerted mechanism (pathway A).

is $0.99 \AA$. On the other hand, the distance $\mathrm{N}-\mathrm{H}$ in the TS is $1.32 \AA$, but absent in the reactant 2-monolaurin. Bond $\mathrm{C}-\mathrm{O}$ is being formed with a length of $1.86 \AA$. The 
optimized geometry of this TS is shown in Figure 2. Regarding the energetics, this TS corresponds to a barrier of $37.5 \mathrm{kcal} \mathrm{mol}^{-1}$ and the formation of the trans-urethane product releases $11.1 \mathrm{kcal} \mathrm{mol}^{-1}$.

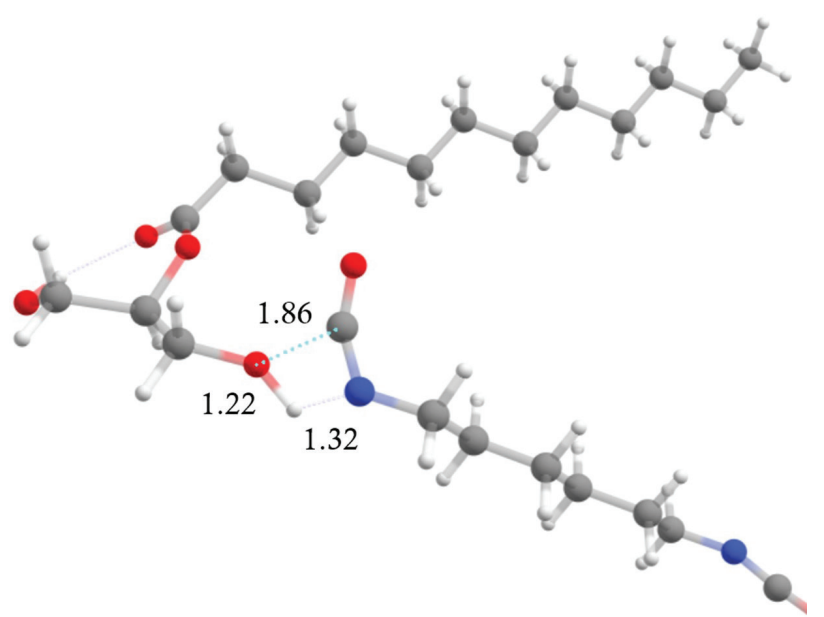

Figure 2. Optimized geometry for the transition state (TS) in the concerted mechanism A.

In Figure 3 we show the energetic profile of the mechanism for the stepwise pathway considered in this work for the reaction of 2-molaurin with 1,6-HDI.

The first step of this mechanism is a nucleophilic attack of the oxygen atom of the hydroxyl in the 2-monolaurin to the carbon of the isocyanate group, corresponding to the TS1 with a barrier of $51.8 \mathrm{kcal} \mathrm{mol}^{-1}$, that immediately forms the intermediate I1. The intermediate I 2 is reached by surpassing a barrier of $3.5 \mathrm{kcal} \mathrm{mol}^{-1}$, which is the TS2.
This step corresponds to an interconversion, turning a $\mathrm{C}-\mathrm{O}$ bond by $153.4^{\circ}$.

Finally, the reaction comes to an end covering a barrier of $28.3 \mathrm{kcal} \mathrm{mol}^{-1}$ (TS3), forming the products, that have an energy of $-11.1 \mathrm{kcal} \mathrm{mol}^{-1}$. In this last step, we have the transfer of the hydrogen from the oxygen to the nitrogen, taking place simultaneously with the vanishing of the double bond $\mathrm{C}=\mathrm{N}$ and formation of a $\pi$-bond in the $\mathrm{C}-\mathrm{O}$ covalent interaction.

A comparison of the two possible pathways here considered clearly shows that the concerted mechanism is the one to govern the reaction since its TS is $14.3 \mathrm{kcal} \mathrm{mol}^{-1}$ smaller than the greatest barrier of the stepwise pathway (TS1). This barrier values are affordable, which implies in a process that can potentially happen at room temperature.

As said above, we focused on lauric acid to explore the reaction mechanism, once it is the most present in babassu oil. However, another fatty acids are also present, and they can also be a source of 2-monoacylglycerol species that can react with the isocyanate to form polyurethanes. Therefore, we have also decided to explore the influence of different fatty acids source in the reaction energetics.

Because concerted mechanism A is the most stable, we use this mechanism to assess the influence of different fatty acids on the energetics. To do so, we have localized all the stationary points for each one of the fatty acids. The energies are shown in Table 1.

As can be seen, there is no significant difference in the transition states for the different 2-monoacylglycerol, neither exists for the products, which means that there are no

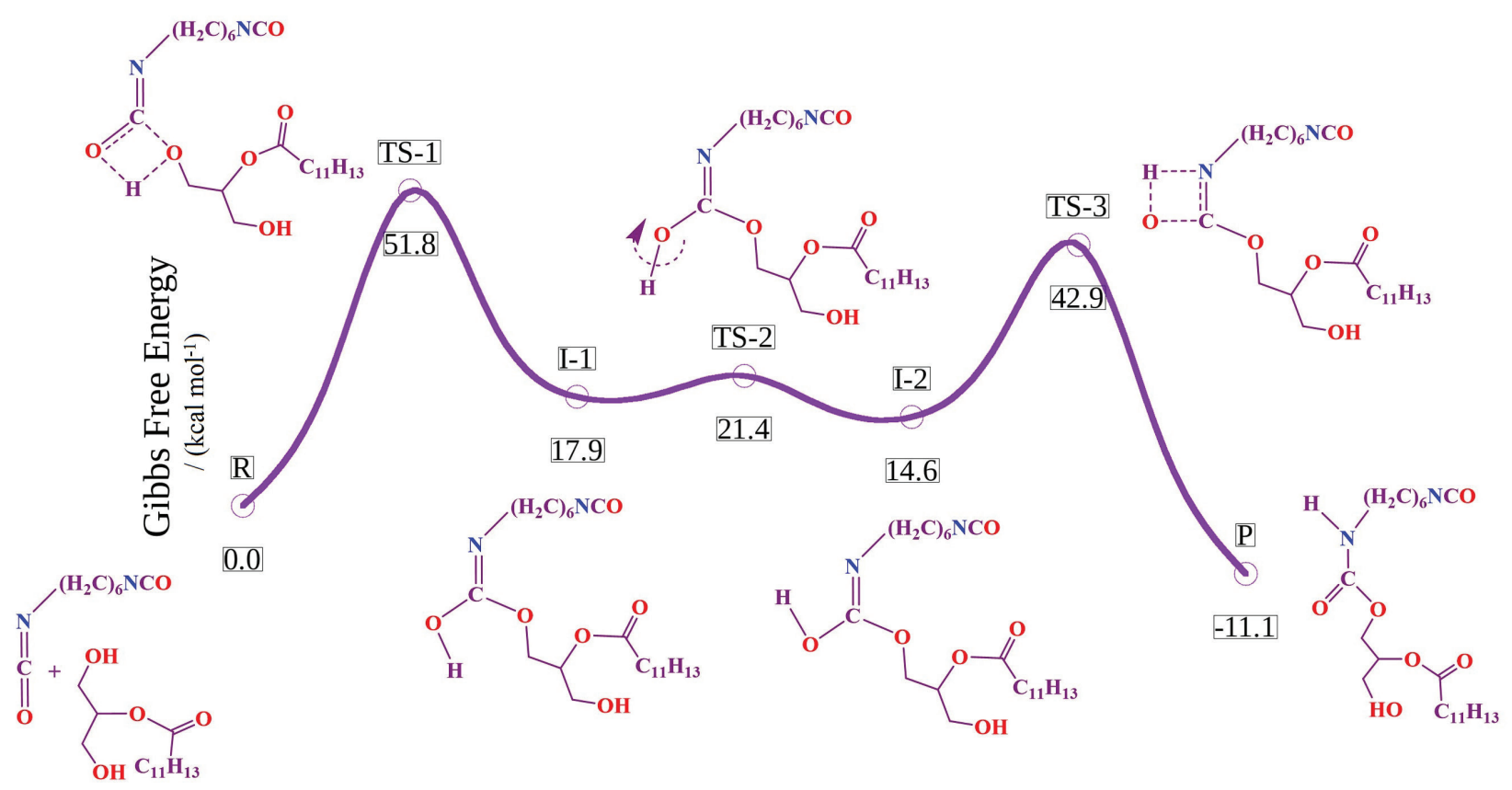

Figure 3. Free energy profile for the reaction of 2-molaurin with 1,6-HDI by the stepwise mechanism (pathway B). 
Table 1. Free energy for reactants (R), transition states (TS) and products (P) in the mechanism for the reactivity of diisocyanate with 2-monoacylglycerol, obtained from different fatty acids

\begin{tabular}{lcccccccc}
\hline & Caprylic acid & Caproic acid & Lauric acid & Myristic acid & Palmitic acid & Stearic acid & Oleic acid & Linoleic acid \\
& C:8 & C:10 & C:12 & C:14 & C:16 & C:18 & C:18:1 & C:18:2 \\
\hline Babassu oil $/ \%$ & 5.0 & 6.0 & 44.0 & 17.0 & 8.0 & 4.5 & 14.0 & 2.0 \\
$\mathrm{R} /\left(\mathrm{kcal} \mathrm{mol}^{-1}\right)$ & 0.0 & 0.0 & 0.0 & 0.0 & 0.0 & 0.0 & 0.0 & 0.0 \\
$\mathrm{TS} /\left(\mathrm{kcal} \mathrm{mol}^{-1}\right)$ & 37.2 & 37.5 & 37.5 & 37.5 & 35.7 & 35.1 & 38.1 & 36.5 \\
$\mathrm{P} /\left(\mathrm{kcal} \mathrm{mol}^{-1}\right)$ & -11.3 & -11.9 & -11.2 & -11.0 & -11.9 & -12.0 & -10.5 & -11.0 \\
\hline
\end{tabular}

aPercentual composition of the babassu oil.

significant differences for the different fatty acids, neither regarding the thermodynamic, nor the kinetic control. Such behavior implies that the composition of the polyurethane product is dependent on the composition of the natural oil. Therefore, to get a homogeneous product, it is necessary to make a separation of the components of the natural oil before the reaction meant to form the polyurethane itself.

To understand the polymerization reaction itself, it is important to have insights about the growth of the polymer chain. Here we consider the process of the dimer formation. Scheme 2 shows potential mechanisms for the dimer formation, as suggested by Shyichuk and co-workers, ${ }^{20}$ while Figure 4 shows the free energy profile for those mechanisms. In it, G-D is the urethane monomer, which is the same product formed in the products $(\mathrm{P})$ explored in mechanism A (Figure 1).

$$
\begin{array}{ll}
\mathbf{G}-\mathbf{D}+\mathbf{G} \rightarrow \mathbf{G}-\mathbf{D}-\mathbf{G}+\mathbf{D} \rightarrow \mathbf{G}-\mathbf{D}-\mathbf{G}-\mathbf{D} & \text { (path I) } \\
\mathbf{G}-\mathbf{D}+\mathbf{D} \rightarrow \mathbf{D}-\mathbf{G}-\mathbf{D}+\mathbf{G} \rightarrow \mathbf{D}-\mathbf{G}-\mathbf{D}-\mathbf{G} & \text { (path II) } \\
\mathbf{G}-\mathbf{D}+\mathbf{G}-\mathbf{D} \rightarrow \mathbf{G}-\mathbf{D}-\mathbf{G}-\mathbf{D} & \text { (path III) }
\end{array}
$$

Scheme 2. Potential mechanisms for the dimerization of the polyurethane. G-D represents the polyurethane, where G stands for the monoglyceride and $\mathrm{D}$ the diisocyanate.

In the path I for the dimer formation, polyurethane G-D can react with the monoglyceride $G$ and subsequently with diisocyanate $\mathrm{D}$ forming the dimer $\mathrm{G}-\mathrm{D}-\mathrm{G}-\mathrm{D}$. For the path II, the G-D reacts first with a diisocyanate D and only afterward it reacts with the monoglyceride $\mathrm{G}$, forming the dimer. Finally, in the path III, the G-D monomer can react directly with another G-D monomer to form the dimer. All those couplings were modeled based on the concerted mechanism, since it is the most favorable mechanism, as already discussed.

As shown in Figure 4, the activation energy for the path III $\left(15.7 \mathrm{kcal} \mathrm{mol}^{-1}\right)$ is smaller than for path I $\left(38.4 \mathrm{kcal} \mathrm{mol}^{-1}\right)$ and path II $\left(35.4 \mathrm{kcal} \mathrm{mol}^{-1}\right)$. In this way, the most favorable mechanism for the dimer formation is the coupling of the previously formed polyurethanes block,
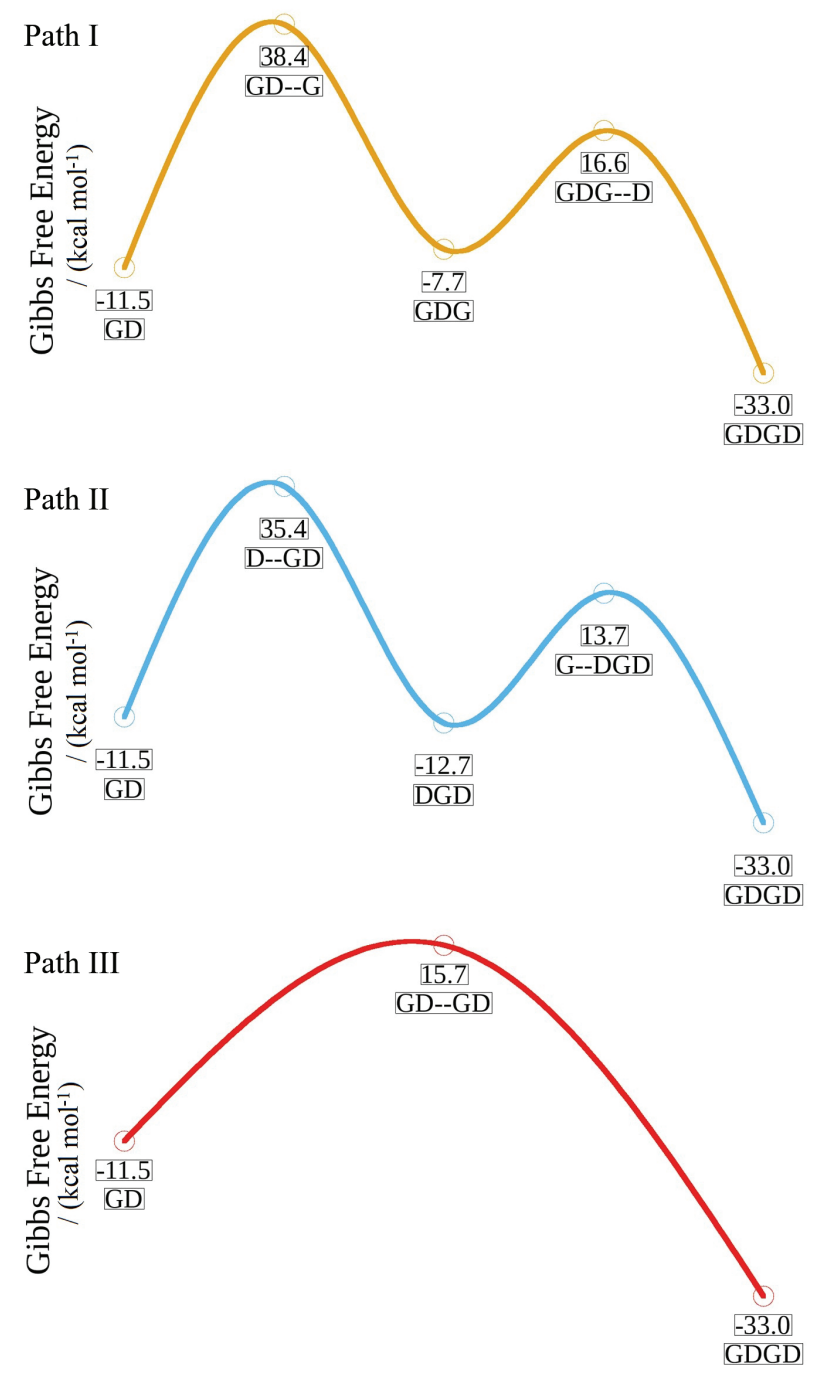

Figure 4. Free energy profiles of the potential mechanisms for dimerization of the polyurethane.

instead of building the polymer by adding a diisocyanate molecule to the polyurethane after a monoacylglycerol (path I) or adding a monoacylglycerol after a diisocyanate (path II). This shows that the urethane formation is mandatory before the growth of the polymeric chain.

We can also see that the dimmer formation is a process even more exergonic $\left(33.0 \mathrm{kcal} \mathrm{mol}^{-1}\right)$ than the polyurethane 
formation $\left(11.1 \mathrm{kcal} \mathrm{mol}^{-1}\right)$. This is an indicative that the polymerization is a living process.

\section{Conclusions}

Our theoretical DFT-based study has shown that the polyurethane formation from 1,6-HDI reacting with 2-monolaurin takes place by a concerted pathway, which involves the transference of the hydrogen in the monoacylglycerol to a nitrogen atom in the 1,6-HDI. The barrier of $37.5 \mathrm{kcal} \mathrm{mol}^{-1}$ indicates that the reaction can take under a mild heating. Analysis of the polyurethane's formation with other fatty acids from the babassu oil did not show any relevant kinetic or thermodynamic difference, implying the importance of using pure fatty acids. The dimerization occurs by a coupling reaction of urethane blocks, instead of building the chain by adding 1,6-HDI after 2-monolaurin. It is presumed that the polymerization also occurs by adding urethane blocks.

\section{Supplementary Information}

Supplementary data are available free of charge at http://jbcs.sbq.org.br as PDF file, containing the benchmarking of different functionals and computed Cartesian coordinates of all molecules reported in the main text.

\section{Acknowledgments}

F. I. S. wants to thank the Brazilian funding agency Coordenação de Aperfeiçoamento de Pessoal de Nível Superior (CAPES), for a schoolarship. J. M. E. M. thanks CNPq (Conselho Nacional de Desenvolvimento Científico e Tecnológicos), process 311538/2017-7 and 310769/2014-0 and 457467/2014-2, for the financial support. We thank CENAPAD-RJ and Lobo-C center for the computational time.

\section{References}

1. Silva, A. L.; Bordado, J. C.; Catal. Rev.: Sci. Eng. 2004, 46, 31.

2. Engels, H. W.; Pirkl, H. G.; Albers, R.; Albach, R. W.; Krause, J.; Hoffmann, A.; Casselmann, H.; Dormish, J.; Angew. Chem., Int. Ed. 2013, 52, 9422.

3. Akindoyo, J. O.; Beg, M. D. H.; Ghazali, S.; Islam, M. R.; Jeyaratnam, N.; Yuvaraj, A. R.; RSC Adv. 2016, 6, 114453.

4. Sardon, H.; Engler, A. C.; Chan, J. M. W.; García, J. M.; Coady, D. J.; Pascual, A.; Mecerreyes, D.; Jones, G. O.; Rice, J. E.; Horn, H. W.; Hedrick J. L.; J. Am. Chem. Soc. 2013, 135, 16235 .
5. Muuronen, M.; Deglmann, P.; Tomović, Ž.; J. Org. Chem. 2019 , 84,8202 .

6. Petrović, Z. S.; Ferguson, J.; Prog. Polym. Sci. 1991, 16, 695.

7. Sardon, H.; Pascual, A.; Mecerreyes, D.; Taton, D.; Cramail, H.; Hedrick, J. L.; Macromolecules 2015, 48, 3153.

8. Coutinho, F. M. B.; Delpech, M. C.; Alves, L. S.; Polímeros 2000, 10, 49.

9. Comí, M.; Lligadas, G.; Ronda, J. C.; Galià, M.; Cádiz, V.; Polymer 2016, 103, 163.

10. Lligadas, G.; Ronda, J. C.; Galiá, M.; Cádiz, V.; Biomacromolecules 2010, 11, 2825.

11. González-Paz, R. J.; Lluch, C.; Lligadas, G.; Ronda, J. C.; Galià, M.; Cádiz, V. A.; J. Polym. Sci., Part A: Polym. Chem. 2011, 49, 2407.

12. Carrazza, L. R.; Silva, M. L.; Ávila, J. C. C.; Manual Tecnológico de Aproveitamento Integral do Fruto do Babaçu; ISPN: Brasília, DF, Brazil, 2012.

13. Antoniassi, R.; Rev. Ceres 2006, 53, 463.

14. Rocha,D.D.Q.;Barros,D.K.; Costa,E.J.C.; deSouza,K.S.;Passos, R. R.; da Veiga, V. F.; Chaar, J. D. S.; Quim. Nova 2008, 31, 1062.

15. Lima, J. R. D. O.; da Silva, R. B.; da Silva, C. C. M.; dos Santos, L. S. S.; dos Santos, J. R.; Moura, E. M.; de Moura, C. V. R.; Quim. Nova 2007, 30, 600.

16. do Nascimento, R. T.; de Sousa e Silva, H.; de Matos, J. M. E.; Santos, M. R. M. C.; J. Polym. Res. 2019, 26, 183.

17. da Cunha, G. P.; Borges, F. M.; Dognani, G.; Bacarin, G. B.; Cabrera, F. C.; Job, A. E.; Matos, J. M. E.; Vega, M. L.; da Cunha, H. N.; J. Appl. Polym. Sci. 2018, 135, 46198.

18. Çoban, M.; Konuklar, F. A. S. A.; Comput. Theor. Chem. 2011, 963, 168.

19. Raspoet, G.; Nguyen, M. T.; McGarraghy, M.; Hegarty, A. F.; J. Org. Chem. 1998, 63, 6878.

20. Cysewski, P.; Król, P.; Shyichuk, A.; Macromol. Theory Simul. 2007, 16, 541.

21. Frisch, M. J.; Trucks, G. W.; Schlegel, H. B.; Scuseria, G. E.; Robb, M. A.; Cheeseman, J. R.; Montgomery Jr., J. A.; Vreven, T.; Kudin, K. N.; Burant, J. C.; Millam, J. M.; Iyengar, S. S.; Tomasi, J.; Barone, V.; Mennucci, B.; Cossi, M.; Scalmani, G.; Rega, N.; Petersson, G. A.; Nakatsuji, H.; Hada, M.; Ehara, M.; Toyota, K.; Fukuda, R.; Hasegawa, J.; Ishida, M.; Nakajima, T.; Honda, Y.; Kitao, O.; Nakai, H.; Klene, M.; Li, X.; Knox, J. E.; Hratchian, H. P.; Cross, J. B.; Bakken, V.; Adamo, C.; Jaramillo, J.; Gomperts, R.; Stratmann, R. E.; Yazyev, O.; Austin, A. J.; Cammi, R.; Pomelli, C.; Ochterski, J. W.; Ayala, P. Y.; Morokuma, K.; Voth, G. A.; Salvador, P.; Dannenberg, J. J.; Zakrzewski, V. G.; Dapprich, S.; Daniels, A. D.; Strain, M. C.; Farkas, O.; Malick, D. K.; Rabuck, A. D.; Raghavachari, K.; Foresman, J. B.; Ortiz, J. V.; Cui, Q.; Baboul, A. G.; Clifford, S.; Cioslowski, J.; Stefanov, B. B.; Liu, G.; Liashenko, A.; Piskorz, P.; Komaromi, I.; Martin, R. L.; Fox, D. J.; Keith, T.; Al-Laham, M. A.; Peng, C. Y.; Nanayakkara, A.; Challacombe, M.; Gill, P. M. W.; Johnson, B.; Chen, 
W.; Wong, M. W.; Gonzalez, C.; Pople, J. A.; Gaussian 09, Revision D.01; Gaussian Inc., Wallingford, CT, USA, 2009.

22. Becke, A. D.; Phys. Rev. A 1988, 38, 3098.

23. Lee, C.; Yang, W.; Parr, R. G.; Phys. Rev. B 1988, 37, 785.

24. Krishnan, R.; Binkley, J. S.; Seeger, R.; Pople, J. A.; J. Chem. Phys. 1980, 72, 650 .
25. McLean, A. D.; Chandler, G. S.; J. Chem. Phys. 1980, 72, 5639.

Submitted: December 18, 2019

Published online: May 22, 2020 